\title{
PESQUISA DE QUALIDADE NO TRANSPORTE PÚBLICO DE CURITIBA: ANÁLISES E CONSIDERAÇÓES
}

\author{
A. C. C. Caracas ${ }^{1}$; M. A. P. Bernardinis ${ }^{2}$; J. T. Bastos ${ }^{3}$ \\ ${ }^{1}$ Graduanda da Universidade Federal do Paraná, Curso de Engenharia Civil. Centro Politécnico, \\ Jd. das Américas, Curitiba/PR \\ ${ }^{2,3}$ Professor da Universidade Federal do Paraná. Centro Politécnico, Departamento de Transportes, bloco V, \\ $J d$. das Américas, Curitiba/PR \\ anacarolinacaracas@hotmail.com ${ }^{1}$,profmarcia.map@gmail.com²,jtbastos@ufpr.br ${ }^{3}$
}

\begin{abstract}
Resumo: A mobilidade urbana é um tema recorrente nos dias atuais, uma vez que deficiências no transporte coletivo influenciam a qualidade de vida no meio urbano, contribuindo para engarrafamentos, poluição sonora e ocorrência de acidentes, entre outros impactos. Devido à clara importância do tema, é essencial estudar a qualidade do transporte coletivo nas cidades, por ser esse modo estratégico para a utilização racional do espaço urbano. Baseado nisso, esse artigo avaliou a qualidade do transporte coletivo na cidade de Curitiba por meio dos resultados da pesquisa de satisfaçáo QualiÔnibus. Os resultados foram analisados em três grupos: o universo total da pesquisa; os que utilizam o ônibus diariamente e dependem do transporte coletivo para seus deslocamentos; e os que utilizam diariamente mas possuem automóvel e habilitação. Como resultados das análises, tem-se que os três perfis apresentam muitas semelhanças, como a predominância na utilização de ônibus que circulam por corredores exclusivos - destacando sua importância. Além disso, a maioria não estaria disposta a pagar mais por um serviço melhor, mesmo estando insatisfeitos com fatores como conforto e segurança. Em uma terceira análise, tem-se que a decisão do terceiro grupo em utilizar o transporte coletivo pode ter motivaçáo financeira ou de fatores externos a essa pesquisa.
\end{abstract}

Palavras-chave: Transporte coletivo, Qualidade, Avaliação, QualiÔnibus, Curitiba.

Abstract: Urban mobility is a recurring theme nowadays due to transit problems influence on quality of life of the urban environment, leading to traffic jams, sound polution and accident occurence, besides other impacts. Considering the evident importance of the theme, it is essencial to study the quality of this transportation mode in cities, since this mode is strategic for the best use of urban space. Therefore, this paper evaluated the quality of Curitiba's transit system through the results of a satisfacion survey: "QualiOnibus". The results were analyzed in three groups: the total universe of the research; those who daily use the bus and depend on mass transit for their journeys; and those who use daily but own a car and a driver's license. The analysis results indicate that all the three profiles present many similarities, such as the predominant use of buses that circulate through exclusive corridors - hightighting their importance. In addition, most of the users would not be willing to pay more for a better service, even though they were unsatisfied with aspects such as comfort and safety. In a third analysis, the decision of the third group to use the transit system may have financial motivation or be related to external facts to this research.

Keywords: Transit, Quality, Evaluation, QualiÔnibus, Curitiba. 


\section{Introduçáo}

A importância do transporte coletivo para a mobilidade urbana já é reconhecida pela sociedade brasileira como parte de uma visão mais sustentável de cidade, que também inclui o aumento de áreas verdes e a redução da utilização de automóveis, entre outras estratégias. Tais princípios se tornaram mais visíveis com a criaçáo do Estatuto das Cidades (Lei 10257/01) e da Lei da Mobilidade (Lei $12.587 / 12$ ), os quais trazem como diretriz a priorização dos modos não motorizados e do transporte público coletivo. Esse último modo tem sido mais incentivado por proporcionar uma utilização mais racional do espaço urbano, acarretando maior igualdade de condiçôes de deslocamentos para os habitantes da cidade (ITDP, 2014).

Para compreender esse funcionamento do sistema de mobilidade urbana são necessários bancos de dados especialmente estruturados para acompanhar a dinâmica do transporte urbano nos municípios. Para isso, em parceira com o Banco Nacional do Desenvolvimento - BNDES, a Agência Nacional de Transportes Públicos - ANTP desenvolveu o Sistema de Informaçóes de Mobilidade Urbana - SIM, que compila dados obtidos por meio de questionários enviados pela ANTP aos responsáveis pelo transporte e trânsito municipal e metropolitano dos municípios com população superior a 60 mil habitantes, o que, em 2003, correspondia a 438 municípios (ANTP, 2014).

O estudo inclui dados comparativos de 2003 até 2014. Um dos primeiros apontamentos do relatório é o ritmo de crescimento no número de veículos, que foi substancialmente maior que o ritmo de crescimento da população (ANTP, 2014). Conforme a média dos dados da Tabela 1, tem-se que a maior parte das viagens é realizada por meios de transporte não motorizados (42,6\%), seguidas pelas realizadas com veículo individual $(29,1 \%)$ e, por último, as que utilizam transporte coletivo (28,3\%). Além disso, o transporte individual apresentou o maior crescimento entre 2003 e 2014, enquanto o transporte coletivo reduziu sua participação percentual e o transporte não motorizado apresentou um aumento pouco significativo. Observou-se também que os anos de 2008 e 2009 apresentaram constância nos três modos de transporte.

Tabela 1 - Evolução das viagens por modo (em porcentagem).

\begin{tabular}{cccccccccccccc}
\hline Ano & $\mathbf{2 0 0 3}$ & $\mathbf{2 0 0 4}$ & $\mathbf{2 0 0 5}$ & $\mathbf{2 0 0 6}$ & $\mathbf{2 0 0 7}$ & $\mathbf{2 0 0 8}$ & $\mathbf{2 0 0 9}$ & $\mathbf{2 0 1 0}$ & $\mathbf{2 0 1 1}$ & $\mathbf{2 0 1 2}$ & $\mathbf{2 0 1 3}$ & $\mathbf{2 0 1 4}$ & M.A. \\
\hline TC & 29,2 & 28,6 & 28,4 & 28,3 & 28,6 & 28,6 & 28,6 & 28,3 & 28,1 & 28 & 27,9 & 27,3 & 28,3 \\
TI & 28 & 28,2 & 28,6 & 28,8 & 29 & 29 & 29 & 29,3 & 29,7 & 29,9 & 29,6 & 29,8 & 29,1 \\
TNM & 42,8 & 43,1 & 43 & 42,9 & 42,6 & 42,4 & 42,4 & 42,3 & 42,2 & 42,1 & 42,5 & 42,9 & 42,6 \\
\hline
\end{tabular}

T.C.: transporte coletivo, T.I.: transporte individual, T.N.M.: transporte não motorizado e M.A.: média aritmética Fonte: ANTP (2014).

Ainda de acordo com a Tabela 1, em 2003, o transporte coletivo representava 29,2\% dos deslocamentos e, em 2014, 27,3\%; enquanto o transporte individual indica aumento: 28 e 29,8\% das viagens, respectivamente. Além disso, o transporte não motorizado é o mais expressivo em todos os 
anos, representando uma média de 42,6\% de participação no transporte entre 2003 e 2014 . Além disso, observa-se que, entre os anos 2003 e 2004, o número de viagens realizadas utilizando o transporte coletivo era superior ao utilizando transporte individual motorizado. Porém, a partir de 2005, esse quadro inverteu e o transporte individual, além de superar o coletivo, apresentou crescimento contínuo até 2012; apesar de uma queda de participação em 2013 e 2014 - tal declínio foi compensado pelo aumento do transporte não motorizado.

No mesmo relatório, há outro indicador que caracteriza esse contexto: o índice de mobilidade (relação entre o número de viagens diárias e a população do município), que pode ser observado na Figura 1. Observa-se que o transporte coletivo foi o único que não obteve crescimento durante esse intervalo de tempo: o indicador variou durante os anos de 0,44 a 0,49 , mas permaneceu igual a 0,46 nos anos de início e término da análise. Além disso, a distribuição modal é semelhante ao intervalo de 2005 a 2014 da Tabela 1: o transporte não motorizado é o mais representativo, seguido pelo individual e, por fim, o coletivo.

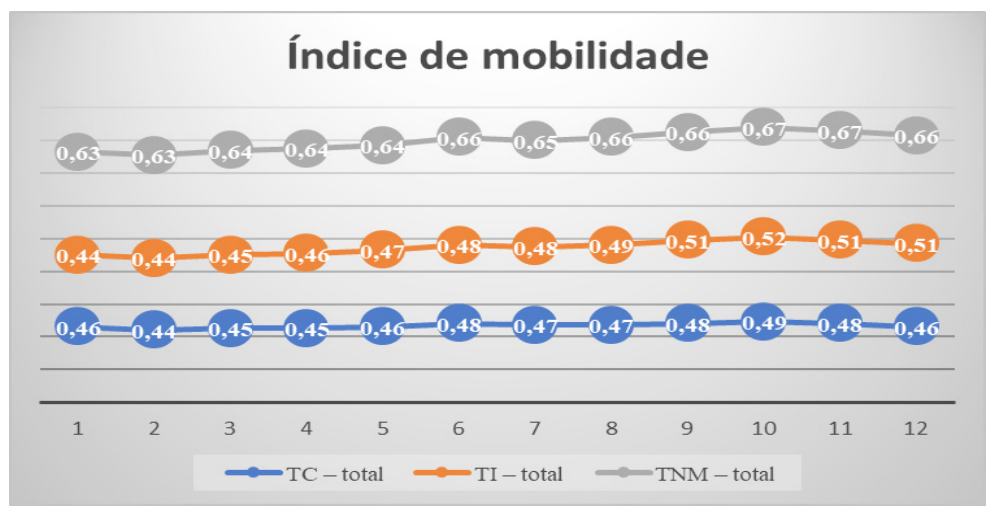

Figura 1 - Índice de mobilidade (viagens por habitante por dia). Fonte: ANTP (2014).

As informaçóes apresentadas na Tabela 1 e na Figura 1 demonstram que o transporte coletivo, apesar de ser fundamental para a mobilidade urbana sustentável, ainda não é priorizado no planejamento da maioria dos municípios brasileiros. A tendência de redução do número de viagens apresentada é preocupante, tendo em vista que pode despertar um processo de aumento da tarifa, o qual, por sua vez, pode desencadear uma nova redução no número de viagens, constituindo um círculo vicioso de degradação da qualidade e da utilização do transporte coletivo.

Em um país de dimensóes continentais como o Brasil, com diferentes realidades urbanas, o cenário relativo ao transporte coletivo pode ser bastante diferente. Por este motivo, é importante o desenvolvimento de pesquisas em âmbito local para levantar as necessidades de melhorias do sistema de transporte coletivo nos diferentes municípios. As pesquisas de satisfação, como a pesquisa QualiÔnibus - objeto de estudo deste artigo - são um exemplo de iniciativa capaz de contribuir para o levantamento de informaçôes em nível local. 
O município de Curitiba é um exemplo de município que apresentou redução do número de viagens no transporte coletivo, sendo um cenário adequado para o desenvolvimento de pesquisas que busquem investigar os motivos que levaram a esta reduçáo, bem como formas de revertê-la. Diante deste contexto, o objetivo do presente artigo é apresentar e analisar os resultados de uma pesquisa de qualidade do transporte coletivo (QualiÔnibus) aplicada em Curitiba.

\section{Metodologia}

A fim de atingir o objetivo proposto, a metodologia foi dividida em três etapas: (1) planejamento da aplicação dos questionários; (2) aplicação dos questionários e construção do banco de dados; e (3) tratamento e análise dos resultados. Os processos envolvem diversos indivíduos e organizaçôes, a saber: as organizaçôes WRI - World Resources Institute e URBS - Urbanização de Curitiba e os pesquisadores. Foram aplicadas, no total, 2008 pesquisas, distribuídas nas linhas de ônibus da cidade de Curitiba.

\subsection{Planejamento da aplicação dos questionários}

Primeiramente, URBS e WRI definiram onde seriam aplicados os questionários. Foi acordado que o número de aplicaçóes em cada linha de ônibus de Curitiba seria definido conforme a porcentagem de passageiros do transporte coletivo que as utilizavam. Dessa forma, foram aplicadas mais pesquisas nas linhas mais utilizadas, a fim de obter resultados mais representativos e fiéis às demandas do sistema.

A pesquisa apresenta cinco modelos diferentes de questionário e é dividida em duas partes: um Módulo Básico - comum a todos os questionários - e um Módulo Detalhado - que varia em cada questionário, tanto em relação ao tema quanto à quantidade de perguntas. Na Figura 2, há como exemplo a primeira página dos módulos básico e detalhado do questionário 1. Nesse artigo, serão abordados os resultados da Pesquisa de Satisfação realizada em 2015 na cidade de Curitiba. Além da capital paranaense, o programa está presente em cidades como Belo Horizonte (MG) e no Rio de Janeiro (RJ). (WRI, 2014) 


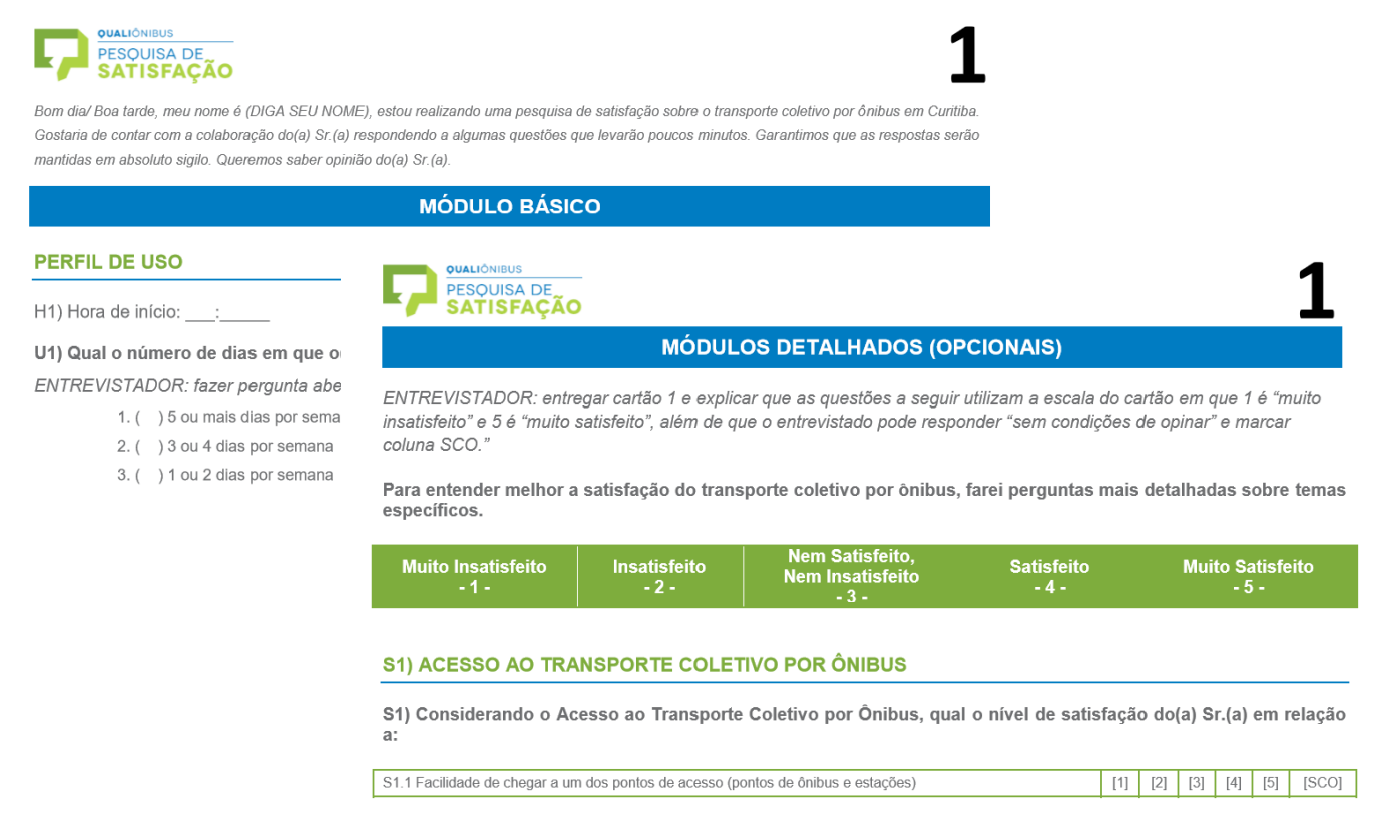

Figura 2 - Recorte do questionário 1, módulos básico e detalhado.

As 2000 pesquisas foram divididas proporcionalmente entre linhas de todos os tipos, sejam elas linhas expressas (como Santa Cândida - Capão Raso), linhas diretas (Pinhais - Campo Comprido), linhas convencionais (Jardim Social/Batel) ou outras. Além disso, foram realizadas entre os dias 12 de novembro e 18 de dezembro, distribuídas entre o período de pico da manhã (30\%), entrepicos (40\%) e o período de pico da tarde (30\%), resultando nos intervalos: das $6 \mathrm{~h}$ às $9 \mathrm{~h}$, das $9 \mathrm{~h}$ às $17 \mathrm{~h}$ e das $17 \mathrm{~h}$ às $20 \mathrm{~h}$, respectivamente.

\subsection{Aplicação dos questionários e construçáo do banco de dados}

Após o planejamento de aplicação, essa tabela foi encaminhada à empresa júnior de Engenharia Civil da Universidade Federal do Paraná, Alcance Engenharia Júnior, que fora contratada pela URBS para gerenciar os pesquisadores, controlar as pesquisas e tabular os dados. Após uma seleção de pesquisadores definida pela proximidade entre a residência do aluno e os pontos de aplicação e pela sua disponibilidade, foram contratados como pesquisadores 32 alunos do curso de Engenharia Civil da mesma universidade, os quais foram treinados pela WRI Brasil.

Além do treinamento, o questionário continha orientaçóes escritas, indicando como se apresentar, explicar a pesquisa e conduzir cada pergunta e como marcar as respostas - um exemplo é a terceira pergunta do módulo básico, que questiona quais os horários em que o entrevistado utiliza o transporte coletivo e permite marcar no máximo três alternativas. Cada pesquisador realizou uma média de 62,5 pesquisas. Com a tabulação dos dados obtidos, foi possível construir uma planilha em Excel. 


\subsection{Tratamento e análise dos resultados}

Apesar de cada questionário conter um módulo básico e um detalhado, foi abordado no presente artigo somente o módulo básico, que apresenta uma amostra maior, uma vez que é idêntico em todos os cinco tipos de questionário. Apesar de inicialmente serem 2008 resultados, foram excluídos alguns questionários que apresentavam erros, entre eles: erros de digitação que permitiam dupla interpretação, problemas nos horários (era necessário marcar o horário de início e de término de cada pesquisa e algumas apresentavam intervalo negativo: o horário de início era maior que o de término) e qualquer erro que indicasse alta possibilidade de fraude. Com essas eliminaçóes, a amostra final foi de 1987 pesquisas.

\section{Resultados}

Diante de uma quantidade expressiva de dados, serão apresentados os resultados obtidos que mais se destacaram, levando em consideração aqueles indicadores de desempenho considerados mais importantes para caracterizar o sistema. Primeiramente, foi possível traçar um perfil dos usuários do transporte público de Curitiba, conforme:

- $64 \%$ utilizam o transporte público todo dia útil;

- $78 \%$ utilizam para atividades pendulares, dos quais 53\% para deslocamentos por motivo de trabalho e $25 \%$ por motivo de estudo;

- Os horários de pico são entre 5 h e $9 \mathrm{~h}$, representando 33\% dos deslocamentos (13\% dos usuários utilizam entre as $5 \mathrm{~h}$ e as $7 \mathrm{~h}, 20 \%$ entre as $7 \mathrm{~h}$ e as $9 \mathrm{~h}$ ) e entre $15 \mathrm{~h}$ e $19 \mathrm{~h}$, somando $34 \%$ dos deslocamentos (11\% utilizam entre as $15 \mathrm{~h}$ e as $17 \mathrm{~h}$ e $23 \%$ entre as $17 \mathrm{~h}$ e as $19 \mathrm{~h}$ );

- $59 \%$ usam ônibus que circulam, por alguma extensão, por corredores exclusivos;

- A média de ônibus utilizados por viagem é de 2,08 ônibus, sendo que 50\% dos entrevistados usam dois ônibus, $24 \%$ usam um e $20 \%$ usam três;

- $42 \%$ dos usuários são cativos, ou seja, não poderiam ter utilizado nenhum outro modal para realizar a viagem;

- Foi apontado por 59\% dos entrevistados que o ônibus enfrenta muito congestionamento;

- Apesar dos pontos críticos apresentados, apenas $24 \%$ dos usuários estariam dispostos a pagar mais por um serviço melhor.

Além desses indicadores, foi obtido que o tempo médio gasto por dia, considerando ida e volta e todos os modais utilizados, é de 1 h e 36 minutos. Se considerarmos apenas os dias úteis do ano, isso 
representa 17 dias do ano gastos apenas com deslocamento. Observou-se também que os principais pontos indicados pela maioria dos passageiros como satisfatórios foram: a facilidade de chegar aos pontos de acesso e circular nas estaçôes e terminais; a facilidade de fazer integração entre linhas de ônibus e outros modos de transporte; a qualidade e quantidade de informação disponível ao cliente sobre linhas, horários e outros; e a confiabilidade (chegada no horário previsto). Os pontos que apresentaram insatisfação foram: a segurança, o conforto, a rapidez e a disponibilidade (horários, locais e intervalo entre ônibus).

Entre os $64 \%$ dos entrevistados que afirmaram utilizar o transporte coletivo durante cinco ou mais dias na semana, o número de usuários cativos aumentou para $49 \%$ (em vez dos $42 \%$ considerando a amostra completa). A finalidade de uso também se modificou para os usuários diários: 65\% afirmaram utilizar para ir ao trabalho e $29 \%$ para estudo, contra $53 \%$ e $25 \%$, respectivamente, para os usuários em geral. Outro fator que apresentou aumento foi o tempo médio de viagem, que passou de 1 hora e 36 minutos para 1 hora e 44 minutos (equivalente a 18 dias por ano).

Ainda considerando os usuários que utilizam o transporte coletivo pelo menos cinco vezes por semana, realizou-se uma terceira análise filtrando os usuários que afirmaram possuir carteira de habilitação e posse associada à disponibilidade de uso de automóvel na residência - com o objetivo de entender os motivos que levam à escolha do transporte coletivo mesmo com a opção do automóvel. Obtiveram-se 176 usuários com esse perfil, o que corresponde a 14\% dessa amostra e 9\% da amostra total. Analisaram-se entâo as mesmas características utilizadas para definir o perfil do usuário do transporte coletivo de Curitiba, obtendo as seguintes informações:

- 74,2\% utilizam o TPU para ir ao trabalho (proporção maior que entre os usuários cativos) e 22,7\% para estudo (proporção menor que entre os usuários cativos);

- $24,9 \%$ utilizam no horário entre $7 \mathrm{~h}$ e $9 \mathrm{~h}$ (contra $21,5 \%$ entre os cativos) e 23,9\% utilizam no horário entre $17 \mathrm{~h}$ e $19 \mathrm{~h}$ (contra $25,8 \%$ entre os cativos);

- $52,3 \%$ utilizam linhas que circulam por corredores exclusivos (proporção menor que entre os usuários cativos);

- Aproximadamente 50\% utilizam 2 ônibus para chegar ao seu destino (somente ida), sem diferença em relação aos usuários cativos;

- O tempo médio é de 1 hora e 45 minutos, muito semelhante ao gasto pelos usuários diários e usuários cativos, de respectivamente 1 hora e 44 minutos e 1 hora e 43 minutos.

Os pontos indicados como satisfatórios por esses usuários foram: o acesso ao transporte, a confiabilidade e a facilidade de fazer integraçôes. Os insatisfatórios foram o conforto, a segurança e a disponibilidade. Em um quadro geral, os entrevistados mostram-se indiferentes ou insatisfeitos. A 
Tabela 2 apresenta um comparativo entre esses usuários diários que poderiam utilizar o automóvel e os usuários cativos do transporte coletivo.

Tabela 2 - Comparativo entre usuários diários cativos e os que possuem automóvel.

\begin{tabular}{ccc}
\hline & Usuário diário cativo (sem carro) & Usuário diário com carro \\
\hline Acesso & 3,1 satisfeitos para cada 1 insatisfeito & 2,8 satisfeitos para cada 1 insatisfeito \\
Disponibilidade & 1 satisfeito para cada 1,1 insatisfeito & 1 satisfeito para cada 1,2 insatisfeitos \\
Rapidez & 1 satisfeito para cada 1 insatisfeito & 1 satisfeito para cada 1 insatisfeito \\
Confiabilidade & 1,2 satisfeito para cada 1 insatisfeito & 1,5 satisfeitos para cada 1 insatisfeito \\
Facilidade de Integração & 2,6 satisfeito para cada 1 insatisfeito & 3,6 satisfeitos para cada 1 insatisfeito \\
Conforto & 1 satisfeito para cada 1,9 insatisfeito & 1 satisfeito para cada 1,7 insatisfeito \\
Segurança & 1 satisfeito para cada 2,2 insatisfeitos & 1 satisfeito para cada 1,5 insatisfeitos \\
Satisfação Geral & 1 satisfeito para cada 1 insatisfeito & 1 satisfeito para cada 1,1 insatisfeito \\
\hline
\end{tabular}

De forma geral, os usuários do transporte coletivo que possuem a possibilidade de utilização do automóvel apresentam um nível de satisfação bastante semelhantes àqueles usuários cativos. A facilidade de integração foi o quesito que apresentou diferença mais significativa nas avaliaçóes entre usuários cativos e não cativos, demonstrando a importância de melhorias na integração para estimular a migração modal tendo em vista que os não cativos manifestaram maior satisfação quanto ao critério. Além disso, os usuários cativos apresentaram maior satisfação quanto ao acesso, reforçando a ideia de que a maior facilidade no transporte pode atrair novos usuários. Outros aspectos como disponibilidade, confiabilidade, conforto e satisfação geral apresentaram diferenças pouco significativas no mesmo sentido.

Com essa análise específica, percebe-se uma maior proporção de usuários que utilizam o TPU para viagens por motivo de trabalho $(74,2 \%)$, além de uma maior concentração dessas viagens nos horários entre $7 \mathrm{~h}$ e $9 \mathrm{~h}$ e menor entre $17 \mathrm{~h}$ e $19 \mathrm{~h}$. Em contrapartida, o tempo de viagem apresentado foi equivalente e o uso de linhas exclusivas foi menor, mas afirmam estar indiferentes quanto à rapidez. Uma provável explicação para tais variaçôes pode estar nas piores condiçóes de deslocamento que a utilização do automóvel proporcionaria nessas situaçôes - elevado tempo de viagem. Por outro lado, os usuários não cativos se mostraram mais exigentes quanto aos aspectos de segurança e conforto - em um possível indicativo de maior sensibilidade dos usuários em relação a esses fatores.

Em uma última análise, identificou-se que 63\% desses usuários utilizavam cartão transporte recarregado pelo empregador, o que pode indicar um incentivo financeiro para essa escolha. Acredita-se também que motivos externos aos pontos abordados pela pesquisa determinem essa decisão, como uso do automóvel por outro morador da casa ou dificuldades com estacionamento (seja por escassez de oferta ou custo elevado). 


\section{Conclusóes}

A partir dos resultados da pesquisa, pode-se observar que os três grupos analisados - todos os usuários, os usuários diários que dependem do transporte coletivo para seus deslocamentos e os diários que poderiam ter utilizado as viagens como condutor de automóvel - apresentam diversas semelhanças, uma vez que, em todos, a metade dos usuários utiliza dois ônibus para chegar ao seu destino, considerando somente ida; as principais finalidades foram trabalho e estudo; e a maioria utiliza ônibus que circulam por corredores exclusivos.

Além disso, todos demonstraram satisfação quanto à facilidade de fazer integraçóes, à confiabilidade (chegada no horário previsto) e o acesso. Assim, identificamos as principais qualidades do nosso sistema de transporte. Porém, houve insatisfação quanto à segurança, à disponibilidade e ao conforto. Entre o universo global da pesquisa, a rapidez também foi classificada como insatisfatória, mas os usuários diários foram indiferentes a esse fator.

Com essa análise, tem-se que um fator importante para a melhoria do transporte coletivo curitibano é o aumento da segurança e do conforto, visto que esses fatores obtiveram maior insatisfação entre todos os usuários. Apesar disso, a maioria afirmou não estar disposta a pagar mais por um serviço melhor e mostrou-se indiferente quanto à satisfação geral, o que pode estar associado a um histórico de altas tarifas sem reflexo esperado na qualidade do transporte.

Em uma última análise, buscaram-se motivos para os usuários diários que possuem automóvel e carteira de habilitação utilizarem o transporte coletivo para seus deslocamentos. Como a avaliação desses passageiros foi bastante semelhante à dos demais, além de 63\% desses usuários utilizarem cartão transporte recarregado pelo empregador, a motivação possivelmente é financeira ou está relacionada a pontos não abordados no questionário, como congestionamentos ou escassez de estacionamentos.

\section{Referências}

[1] ASSOCIAÇÃO NACIONAL DE TRANSPORTES PÚBLICOS. Sistemas de Informaçóes da Mobilidade Urbana - Relatório Comparativo 2003-2014. Julho de 2016. Disponível em: <http://files.antp.org.br/2016/9/3/ sistemasinformacao-mobilidade--comparativo-2003_2014.pdf>. Acesso em: 8 maio 2017.

[2] ASSOCIAÇÃO NACIONAL DE TRANSPORTES PÚBLICOS. Sistemas de Informaçóes da Mobilidade Urbana - Relatório Geral 2014. Julho de 2016. Disponível em: <http://files.antp.org.br/2016/9/3/ sistemasinformacao-mobilidade--geral_2014.pdf>. Acesso em: 8 maio 2017.

[3] INSTITUTE FOR TRANSPORTATION AND DEVELOPMENT POLICY. Lei de Mobilidade Urbana 12.587/12. Disponível em: <http://2rps5v3y8o843iokettbxnya.wpengine.netdna-cdn.com/wp-content/ uploads/2014/11/ITDP-Brasil_Informativo-sobre-Lei-Nacional-de-Mobilidade-Urbana_em-PT_vers\%C3\%A3oWEB.pdf>. Acesso em: 5 maio 2017. 